\title{
INVESTIGATION ON INFLUENCE OF BIO MATERIALS IN INTERNAL CURING MORTAR
}

\author{
A. Selvi \\ Assistant Professor, Department of Civil Engineering, \\ Unnamalai Institute of Technology, Kovilpatti, Tuticorin, Tamilnadu, India
}

\begin{abstract}
Curing plays a main role to mitigate the cracks due to autogenous and drying shrinkage. In general due to the scarcity of water and weather condition curing is not done properly. In this paper, internal curing of high performance mortars using presaturated Bio-LWA from sugarcane bagasse ash and extraction of milk from caltropis gigantea were studied. Firstly the strength of mortars were studied using partial replacement of fine aggregate with pre-saturated Bio-LWA at various proportions( $20 \%, 25 \%$ \& $30 \%$ by weight of fine aggregate) which is act as a internal curing agent. The Bio-LWA has high porosity and coarse structure which release the water during cement hydration which reduce the self-desiccation and shrinkage of mortars. Secondly the extraction of milk from calatropis gigantea used as internal curing agent (at the proportion of $0.3 \%$ by weight of cement and thirdly, along with Bio-LWA, the milk extracted from calatropis gigantia at the proportion of $0.3 \%$ by weight of cement ) used as a internal curing agent. The mechanical and durability of mortars were studied. Then these results are validated to the conventional mortar.
\end{abstract}

Keywords: Bio-LWA, calatropis gigantia, intrnal curing, high performance mortar.

Cite this Article: A. Selvi, Investigation on Influence of Bio Materials in Internal Curing Mortar. International Journal of Civil Engineering and Technology, 11(5), 2020, pp. 40-46.

https://iaeme.com/Home/issue/IJCIET?Volume=11\&Issue $=5$

\section{INTRODUCTION}

Curing is the process to protect the concrete from loss of moisture which is inevitable for cement hydration. It is also act as a keyplayer to mitigate the cracks. Due to the extreme weather condition, the water are evaporating with a short span of time. In general, the total amount of water required for curing is equal to one third of total amount of water required for whole construction. In some areas, the insufficient amount of water is available to curing because of water scarcity. Its leads to the shrinkage problems in the concrete. Due to the low permeability and porosity, the external curing is not a efficient one. Because it increase the self desiccation property which leads to occurrence of cracks due to auto geneous and drying shrinkage. To overcome this problem, internal curing is one of the solution. According to ACI-308 code states that " internal curing is the process which is the internally available water for cement hydration which doesn't part of mixing water"[1]. 


\section{A. Selvi}

This paper leads to the internal curing using bio-derived waste materials. The bagasse ash is the waste material from sugarcane after extraction on sugar. According to the senses, 1 ton of sugarcane produce the $280 \mathrm{~kg}$ of bagasse ash. These material is disposed by land dumping. In order to utilize these materials, which is used in construction field. It used in construction field at various usage like fiber in order to the increase compressive strength. In this paper sugarcane bagasse ash used as a internal curing agent which is partially replacement with natural aggregate [10]. Calatropis gigantea is the waste plant which requires less amount of water for its growth. The extraction of milk from caltropis gigantea is used as a internal curing agent which mixed with water before used to concrete.

\section{RESEARCH SIGNIFICANCE}

When the concrete mixture contains more than one cementitious materials, the amount of water required for curing is more. If it is not readily available, it will cause cracks in the concrete. The Bio-LWA has a coarse structure. So it absorbed water previously which is released during cement hydration to prevent the concrete from moisture. It reduce the labour cost for curing. In high rise building and conjucted place, ordinary curing is inefficient. Moreover the bagasse ash and milk from CG is the waste materials. It doesn't create economical problems.

\section{MATERIALS}

\subsection{Bio-LWA}

Bio-LWA made from sugarcane bagasse fly ash obtained from sugar factory after extraction of sugar. First to burn the sugarcane bagasse using incineration process to make the fly ash. Then these fly ash mixed with binder (sodium bentonite) to produce homogenous mixture. Using rotatory drum, these mixture converted into pellets. The water was sparing depends upon slide angle during pellataization process. These pellets are heated at $1100^{\circ} \mathrm{c}$ for 24 hours. Then it is cooled at ambient temperature for 24 hours. These were sieved at the size of $500 \mathrm{~mm}$ to $1 \mathrm{~mm}$. these pellets are soaked at water at vacuum temperature for 24 hours before using in mortars. It contains $91 \% \mathrm{sio}_{2}, 2.1 \% \mathrm{Al}_{2} \mathrm{O}_{3}, 1.5 \% \mathrm{Fe}_{2} \mathrm{O}_{3}, 1.1 \mathrm{CaO}, 1.5 \mathrm{~K}_{2} \mathrm{O} 0.9 \mathrm{P}_{2} \mathrm{O}_{5} \&$ $0.4 \mathrm{TiO}_{2}$ by the weight $[11]$.

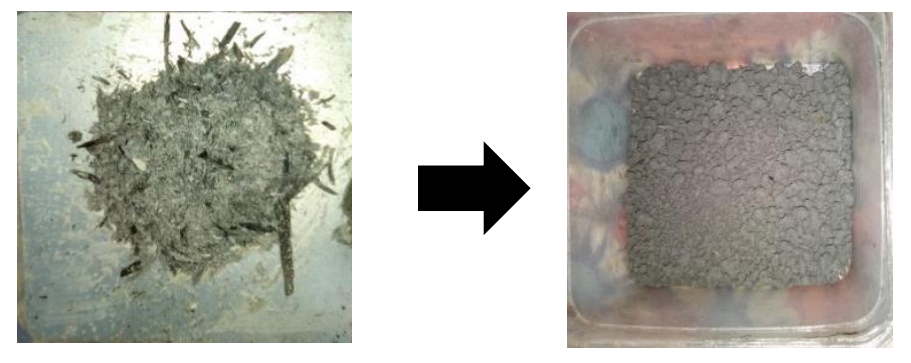

Figure 1 Bagasse ash into LWA

\subsection{Calatropis Gigantia}

Calatropis gigantia is plant which grows without any special care of water. It grows at both fields and terrians. It $\mathrm{pH}$ is found to be 5.5 which is similar to $\mathrm{pH}$ of poly ethylene glycol (chemical internal curing agent) [8]. The milk was extracted from this plant by mannualy. 


\subsection{High Performance Mortar}

The mortar mix contains one or more cementitious materials such as fly ash, silica fume, slag and etc., it is called high performance mortar. It has high strength and high durability when compared to conventional mortar. In this paper, fly ash was replaced by a cement at $30 \%$ [6].

These mortar contains cement, flyas, natural aggregate (river sand), Bio-LWA, milk extracted from CG and super plasticizers (if necessary). OPC 53 grade cement were used in the project [7]. The specific gravity was obtained as 3.18. The class f flyash was used which specific gravity was 1.65 . The flyash was obtained from Tuticorin thermal plant. The river sand which specific gravity was 2.61 was used. These sand from zone 2. Its fineness modulus was 3.12. High range water reducing CONFLAST Fe- 430 SNF (Sulphonated Naphthalein Formaltyhyde) were used when it was necessary

There were three types of specimen were produced in this project. First type contains conventional mortar without any internal curing agents. The second types contains Bio-LWA as a internal curing agent. The last type contains Bio-LWA and milk from CG as a internal curing agent.

The water-cement ratio was taken as $0.3,0.4 \& 0.5$ for conventional mortar, Then optimized value obtained as 0.4 according to the compressive strength. So water-cement ratio taken as 0.4 for internal curing.

The mortar mould was cube at a size of $7.06 \mathrm{~cm}$ at each side. The mix ratio was taken 1:3. Voids in the sand assumed as a $60 \%$. So the required amount of materials as $1.6 \%$. Table 1 shows the materials required for 1 mortar of this project.

Table 1 Materials quantity for 1 mortar

\begin{tabular}{|l|c|}
\hline \multicolumn{1}{|c|}{ Materials } & Quantity \\
\hline Cement & $0.142 \mathrm{~kg}$ \\
\hline Flyash & $0.061 \mathrm{~kg}$ \\
\hline Fine aggregate & $0.811 \mathrm{~kg}$ \\
\hline
\end{tabular}

Table 1 shows the proportions used in the each specimen. The Bio-LWA in saturated form and the milk from CG soluble in water before used in mortar.

Table 2 Specimen details

\begin{tabular}{|c|c|c|c|c|c|c|c|}
\hline $\begin{array}{c}\text { Specimen } \\
\text { specification }\end{array}$ & \multicolumn{2}{|c|}{$\begin{array}{c}\text { Cementious } \\
\text { material }\end{array}$} & \multicolumn{2}{|c|}{$\begin{array}{c}\text { Fine } \\
\text { aggregate }\end{array}$} & $\begin{array}{c}\text { Calatropis } \\
\text { gigantia }\end{array}$ & w/c ratio & Quantity \\
\cline { 2 - 5 } & $\begin{array}{c}\text { Cement } \\
(\boldsymbol{\%})\end{array}$ & $\begin{array}{c}\text { Flyash } \\
(\boldsymbol{\%})\end{array}$ & $\begin{array}{c}\text { Sand } \\
(\boldsymbol{\%})\end{array}$ & $\begin{array}{c}\text { Sba } \\
(\boldsymbol{\%})\end{array}$ & & & \\
\hline CB & 70 & 30 & 100 & - & - & $0.35,0.4,0.45$ & 3 \\
\hline CSB1 & 70 & 30 & 80 & 20 & - & 0.4 & 3 \\
\hline CSB2 & 70 & 30 & 75 & 25 & - & 0.4 & 3 \\
\hline CSB3 & 70 & 30 & 70 & 30 & - & 0.4 & 3 \\
\hline CSCB & 70 & 30 & 75 & 20 & 0.3 & 0.4 & 1 \\
\hline CCB & 70 & 30 & 75 & - & 0.3 & 0.4 & 1 \\
\hline
\end{tabular}




\section{A. Selvi}

\section{TEST \& RESULT}

\subsection{Water Absorption}

The Bio- LWA were dried at $100^{\circ} \mathrm{c}$ about 24 hours. It were weighed and notated as $\mathrm{w}_{1}$. Then it were soaked at water about 24 hours. It were weighed as $w_{2}$ after filtration of water. As per ASTM C1761, the minimum water absorption of LWA as 5\% of mass [2]. The LWA was freed from surface water after 24 hours. Table 3 shows the water absorption of light weight aggregate.

Table 3 Water absorption

\begin{tabular}{|l|c|}
\hline \multicolumn{1}{|c|}{ Description } & weight \\
\hline $\begin{array}{l}\text { Weight before saturated } \\
\left(\mathrm{w}_{1}\right)\end{array}$ & $50 \mathrm{gms}$ \\
\hline $\begin{array}{l}\text { Weight after saturated } \\
\left(\mathrm{w}_{2}\right)\end{array}$ & $56 \mathrm{gms}$ \\
\hline$\%$ of absorption & $12 \%$ \\
\hline
\end{tabular}

\subsection{SEM Analysis}

Fig 2 shows the SEM analysis of light weight aggregate. It shows the it has a coarse structure and at the size of $100 \mu \mathrm{m}$ [3]. These white color shades in figure shows the coarse surface.

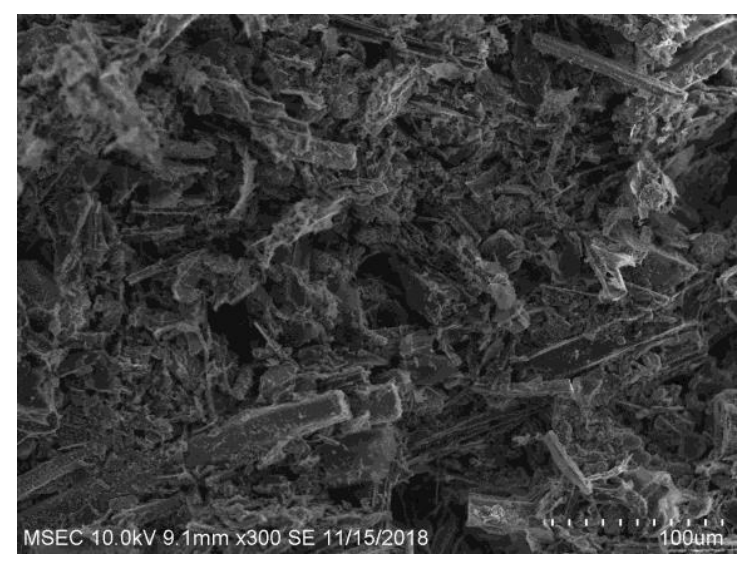

Figure 2 SEM analysis

\subsection{XRF Analysis of Sugarcane Bagasse Ash}

XRF results shows it has potassium content at maximum level. According to "Effect of Potassium Chloride $(\mathrm{KCl})$ on Ordinary Portland Cement (OPC) Concrete" while potassium content increase the compressive and tensile strength increased. According to "ANALYSIS OF PROPERTIES OF CONCRETE USING POTASSIUM POWDER AS ADMIXTURE" Usage of potassium powder in concrete reduces the temperature emitted due to exothermal reaction. Thus gives better results hence we can use this potassium powder where the temperature and the emitting temperatures place a crucial role in construction and maintenance [11] [12]. 

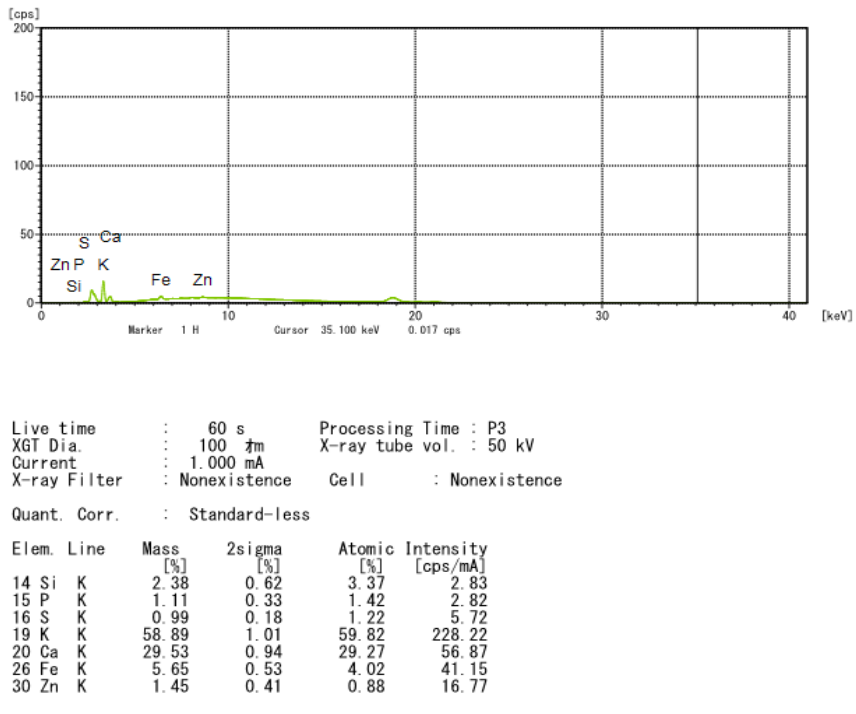

Figure $3 \mathrm{XRF}$ analysis

\subsection{Compressive Strength}

These specimen were tested with universal compressing testing machine at constant rate of loading after 28 days curing. Specimen CSB1, CSB2, CSB3, CSCB \& CCB test results are validated with specimen $\mathrm{CB}$ to check wheather this replacement satisfy our needs or not. In this paper, four types of specimen were prepared. They were conventional and replacement of LWA with $20 \%, 25 \%, 30 \%$ namely as A, B1,B2 \& B3 respectively.

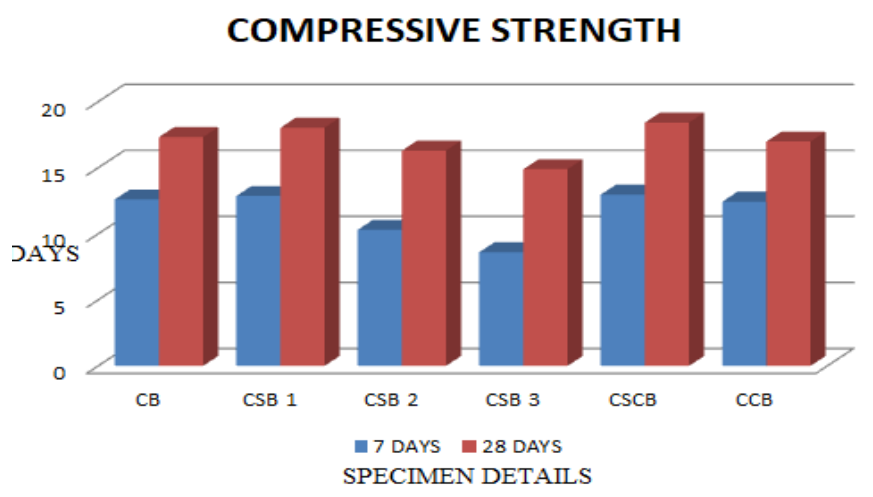

Figure 4 Compressive strength

The use of sugarcane bagasse ash aggregate and extraction of milk from calatropis gigantia as a self curing agent couldn't affect the mechanical property. The higher amount of replacement of LWA decrease the compressive strength. The separate usage of milk from CG doesn't affect the mechanical property much.

\subsection{Drying Shrinkage Test}

This test method describes the procedure for determining the drying shrinkage or change in length of concrete specimen due to changes in moisture content. A length measuring apparatus incorporating a dial gauge capable of measuring the length accurately to $0.005 \mathrm{~mm}$ is shown in figure 4.5. The mould size of $200 \mathrm{~mm}$ x $40 \mathrm{~mm}$ x $40 \mathrm{~mm}$ is shown in figure 4.4 Length comparator measures the initial drying shrinkage of concrete. Drying oven capable of 


\section{A. Selvi}

maintaining a temperature of $27 \pm 1^{0}$. Table 4 shows the reading taken from the length comparator for 30 days. and the table 5 shows the calculation of $\%$ of drying shrinkage.

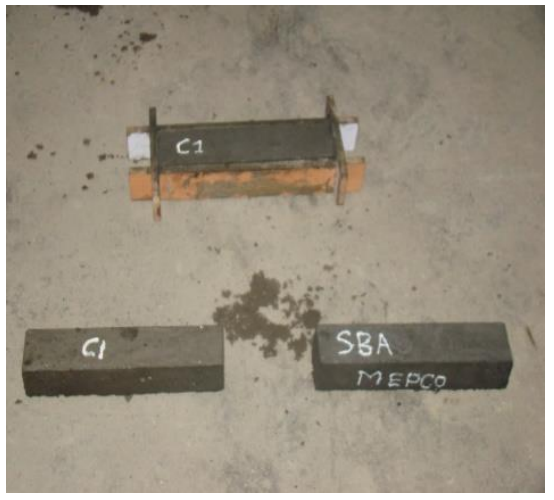

Figure 5 Specimen Size $200 \mathrm{~mm} \times 40 \mathrm{~mm} \times 40 \mathrm{~mm}$

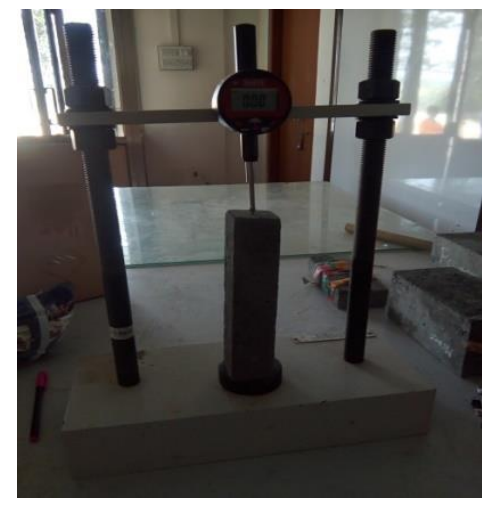

Figure 6 Length comparator

Table 4 Shrinkage readings

\begin{tabular}{|c|c|c|c|c|c|c|c|c|c|}
\hline \multirow[t]{2}{*}{ SAMPLE } & \multicolumn{9}{|c|}{$\begin{array}{l}\text { Least count : } 0.01 \mathrm{~mm} \text { Length of the specimen in } 210 \mathrm{~mm}(\text { including ball) temperature }=\ldots+ \\
27^{\circ} \mathrm{C} \text { at } 72 \text { hours. }\end{array}$} \\
\hline & R 1 & R 2 & R 3 & R 4 & R 5 & R 6 & R 7 & R 8 & R9 \\
\hline $\mathrm{CG}$ & 17.84 & 17.85 & 17.88 & 17.89 & 17.90 & 17.92 & 17.92 & 17.95 & 17.97 \\
\hline SBA & 15.22 & 15.23 & 15.25 & 15.25 & 15.26 & 15.30 & 15.33 & 15.35 & 15.37 \\
\hline $\mathrm{C}-1$ & 18.39 & 18.41 & 18.41 & 18.44 & 18.45 & 18.47 & 18.49 & 18.50 & 18.50 \\
\hline $\mathrm{S}+\mathrm{C}$ & 16.08 & 16.08 & 16.08 & 16.08 & 16.08 & 16.10 & 16.12 & 16.16 & 16.21 \\
\hline
\end{tabular}

Table 5 Drying shrinkage result

\begin{tabular}{|c|c|c|c|c|}
\hline & $\begin{array}{c}\text { INITIAL } \\
\text { READING } \\
(\mathbf{m m})\end{array}$ & $\begin{array}{c}\text { FINAL } \\
\text { READING } \\
(\mathbf{m m})\end{array}$ & $\begin{array}{c}\text { LENGTH OF } \\
\text { MEMBER } \\
(\mathbf{m m})\end{array}$ & \% OF SHRINKAGE \\
\hline C-1 & 209.816 & 209.815 & 210 & 0.000479 \\
\hline S+C & 209.839 & 209.838 & 210 & 0.000476 \\
\hline SBA & 209.848 & 209.846 & 210 & 0.000553 \\
\hline CG & 209.822 & 209.820 & 210 & 0.000952 \\
\hline
\end{tabular}

As per IS6442 - PART II 1979 [13]

$\%$ of drying shrinkage $=\frac{l 1-l 2}{L} \times 100$

Where, 11 - initial reading

12 - final reading

$\mathrm{L}$ - orginal length of specimen

As per IS6442 - PART II 1979, $0.005 \%$ of shrinkage is permissible.

\section{CONCLUSION}

This paper is the study of bio derived materials as internal curing agent. The SEM analysis and water absorption test shows, the LWA has coarse structure and high water absorption behaviour. So it gives more efficiency while it act as a IC agent. Moreover it doesn't affect the mechanical property of the mortar. But the figure 4.3 shows the increase in LWA, decrease in weight. So it comes light weight concrete. So the compressive strength is lesser than control specimen. There is not much significant difference of $\%$ of shrinkage between the 
control and replacement specimen. Moreover these values are within the permissible value. Instead of chemical self curing agent, the natural materials are used as a internal curing agent.

\section{REFERENCES}

[1] 308R-01: Guide to curing concrete. American Concrete Institute, Farmington Hills, MI, USA.

[2] ASTM, ASTM C642-97: Standard test method for density, absorption and voids in hardened concrete. ASTM International, West Conshohocken, PA, USA. 2008.

[3] Dhir RK, Hewlett PC and Dyer TD, "The influence of microstructure on the physical properties of self-curing concrete". ACI Materials Journal 93(5): 1-7, 1996.

[4] 196-ICC Internal curing of concrete -International Union of Laboratories and Experts in Construction Materials, Systems and Structures.

[5] IS 456:2000 - "Indian Standard Code of Practice for Plain and Reinforced Concrete".

[6] IS12269 (1987) - "Indian standard for specification for 53 grade OPC", reaffirmed January 1999.

[7] R. Malathy et al, "Experimental Study on Strength and Durability Properties of Bio-SelfCured Fly Ash Based Concrete under Aggressive Environments", International Journal of Structural and Construction Engineering Vol:11, No:3, 2017.

[8] H.K. Kim et al, "Internal-curing efficiency of cold-bonded coal bottom ash aggregate for high-strength mortar" Construction and Building Materials 126, 1-8, 2016.

[9] "Internal curing of high performance mortar using bottom ash" Mateusz Wyrzykowski, Sadegh Ghourchian, Sakprayut Sinthupinyo, Natechanok Chitvoranund, Tipwimol Chintana, Pietro Lura Cement and Concrete Composites 71, 1-9. 2016.

[10] "Internal curing with lightweight aggregate produced from biomass-derived waste" Pietro Lura, Mateusz Wyrzykowski, Clarence Tang, Eberhard Lehmann, Cement and Concrete Research 59, 24-33. 2014. 